\title{
CONCEPÇÕES DE AMBIENTE E EDUCAÇÃO AMBIENTAL DE PROFESSORES: O PADLET COMO UMA FERRAMENTA INTERATIVA
}

\author{
Anderson de Souza Moser ${ }^{1}$ \\ Aline de Gregório² \\ Elocir Aparecida Correa Pires ${ }^{3}$ \\ Ana Lucia Olivo Rosas Moreira ${ }^{4}$
}

Resumo: Este artigo investigou por meio da ferramenta Padlet, as concepções de ambiente e EA de professores participantes de um processo de formação continuada em EA e Educomunicação. A pesquisa é de cunho qualitativo e utilizou como instrumento de coleta dos dados um mural interativo no recurso Padlet e gravações em áudio. Para análise das concepções utilizamos três concepções de ambiente (natureza, recurso e objeto de transformação/Local de emancipação), bem como as principais macrotendências políticopedagógicas de EA (conservacionista, pragmática e crítica). O Padlet se mostrou como uma ferramenta eficaz na investigação das concepções e possibilitou uma reflexão oportuna a formação crítica dos professores em EA.

Palavras-chave: Socioambiental; Ensino; Formação Continuada.

Abstract: This article investigated through the Padlet tool, the conceptions of environment and $\mathrm{EE}$ of teachers participating in a process of continuing education in EE and Educommunication. The research is of a qualitative nature and used an interactive mural on the Padlet resource and audio recordings as an instrument of data collection. For the analysis of the conceptions we used three conceptions of environment (nature, resource and object of transformation / Place of emancipation), as well as the main macro-pedagogical trends of EE (conservationist, pragmatic and critical). The Padlet proved to be an effective tool in the investigation of conceptions and allowed for a timely reflection on the critical formation of teachers in EE.

Keywords: Socio-environmental; Teaching; Teacher Training.

1 Universidade Estadual de Maringá. E-mail: anderson_moser@live.com.

2 Universidade Estadual de Maringá. E-mail: alinebio130@gmail.com.

3 Universidade Estadual do Oeste do Paraná. E-mail: lupetrie10@hotmai.com.

4 Universidade Estadual de Maringá.E-mail: alormoreira@gmail.com. 


\section{Introdução}

\section{Introdução}

O presente contexto aponta a relevância de discutir sobre o papel que a humanidade ocupa em relação à degradação dos ambientes naturais, do modelo econômico desenfreado e das questões sociais e culturais que envolvem as problemáticas ambientais. Para Zupelari e Wick (2015), refletir sobre o contemporâneo é pensar em alternativas capazes de auxiliar no enfrentamento da crise planetária que está posta. Para auxiliar nessa tarefa árdua, defendemos que a Educação Ambiental (EA adiante) emerge como uma das possíveis alternativas para fazer frente a essa realidade, sendo ela definida na Política Nacional de Educação Ambiental - PNEA como:

[...] os processos por meio dos quais o indivíduo e a coletividade constroem valores sociais, conhecimentos, habilidades, atitudes e competências voltadas para a conservação do meio ambiente, bem de uso comum do povo, essencial à sadia qualidade de vida e sua sustentabilidade (BRASIL, 1999, artigo 1ํ).

Em conformidade ao que expressa essa política pública, a EA deve ser entendida como um componente essencial e permanente da educação nacional, presente de forma articulada em todos os níveis e modalidades de ensino (BRASIL, 1999). Todavia, ela não é uma prática neutra e despolitizada, pois expressa diferentes valores, posicionamentos e representações sobre 0 mundo (BRASIL, 2012). Nesse sentido, os professores são de fundamental importância para a inserção da EA na escola, de modo a favorecer com a formação de cidadãos reflexivos e críticos perante as questões socioambientais (JACOBI, 2005).

Os processos educativos e ambientais podem ser realizados de diferentes formas, porém nem todas as estratégias empregadas possibilitam que as temáticas ambientais sejam abordadas sob um caráter crítico, emancipatório e transformador. Como exemplo, Sauvé (2005) denomina de "correntes" as distintas possibilidades para trilhar a EA, sendo elas: Humanista, Conservacionista, Sistêmica, Problematizadora, Naturalista, Científica, Moral, Biorregionalista, da Sustentabilidade, Crítica, Etnográfica, Feminista, entre outras propostas. No cenário brasileiro, destaca-se o referencial teórico de Layrargues e Lima (2011, 2014), visto que identificaram e organizaram as características, potencialidades e trajetórias de três macrotendências políticopedagógicas de EA: conservacionista, pragmática e crítica. Os autores analisaram os empasses discursivos, teóricos e políticos presentes na disputa pela hegemonia do campo. 
Em cada macrotendência de EA é expressa uma concepção sobre o ambiente, conforme Reigota (2005), o modo de pensar e perceber o ambiente tem influência direta nos encaminhamentos pedagógicos realizados em sala de aula. Isto traz à tona a pertinência do desenvolvimento de atividades de pesquisa que investiguem as concepções dos professores em exercício, ou seja, como esses profissionais compreendem o ambiente, a EA e embasam as suas práticas pedagógicas frente as questões socioambientais.

Para melhor entendimento de como os sujeitos compreendem o ambiente e a EA, diferentes estratégias e recursos podem ser utilizados, como desenhos, entrevistas, gravuras (GARRIDO; MEIRELLES, 2014), fotografias (KATAOKA et al., 2017), questionários (VILAR et al., 2008), entre outros.

$\mathrm{Na}$ investigação do presente estudo, foi utilizada a ferramenta Padlet, um mural interativo virtual que possibilita a postagem de textos, imagens, vídeos, entre outros arquivos (MOTA; MACHADO; CRISPIM, 2017). Trata-se de uma ferramenta que funciona com o auxílio da internet e pode ser acessada por meio do hiperlink: https://pt-br.Padlet.com/. Para ter acesso ao recurso é necessário criar uma conta com o e-mail ou Facebook, sendo que para o perfil gratuito existe um limite de murais que podem ser criados (PADLET, 2020). Silva e Lima (2018) complementam que o Padlet permite a interação dos sujeitos, difundindo ideias, cultura, democratizando as informações de forma a construir o conhecimento em um contexto diferente da tradicional sala de aula. Nesse sentido, esta pesquisa parte da ideia de que o uso dessa ferramenta virtual interativa pode potencializar as ações de ensino e pesquisa de EA.

Diante do exposto, o presente artigo apresentará a investigação realizada por meio da ferramenta Padlet, as concepções de ambiente e EA de professores da Educação Básica participantes de um processo de formação continuada em EA. O estudo procede de um processo de formação continuada em EA e Educomunicação intitulado de "A Educomunicação como uma ferramenta para a inserção da Educação Ambiental no contexto escolar" (Proc. no 1771/2019-PCM/UEM). Este processo formativo se refere a resultados parciais de uma pesquisa de mestrado em Educação para a Ciência e a Matemática da Universidade Estadual de Maringá (UEM), aprovada pelo Comitê de Ética em Pesquisa Envolvendo Seres Humanos COPEP-UEM sob o parecer no. 3.214.257/2019.

\section{Metodologia}

Este estudo é de natureza qualitativa, visto que é constituído por informações descritivas e a análise dos dados busca o significado que os sujeitos atribuem às coisas e à vida, focalizando mais o processo em relação ao produto (LUDKE; ANDRÉ, 1986).

A pesquisa compreende um recorte de um curso de formação continuada em EA e Educomunicação, realizado nas dependências de uma universidade pública do Paraná-PR. Destaca-se que para planejar o referido 
curso, inicialmente as concepções de ambiente e EA dos professores foram obtidas por meio de questões abertas em um questionário. No entanto, no decorrer da intervenção, considerou-se que a utilização do Padlet como instrumento de coleta de dados seria importante, considerando que a ferramenta pode complementar as informações já coletadas no questionário inicial e evidenciar se os participantes da pesquisa modificaram (ou não) suas concepções iniciais sobre o tema. Acredita-se, também, que o Padlet se configura como uma alternativa acessível no contexto escolar ao ser empregada pelos professores em ações pedagógicas com os seus alunos.

\section{A atividade na ferramenta Padlet}

No primeiro encontro do curso, sugeriu-se uma atividade no software Padlet, a qual se baseou na inserção de uma imagem que melhor representava a visão de ambiente de cada participante (Figura 1). Para que a atividade fosse realizada, foi encaminhado um link disponibilizado pelo próprio software via WhatsApp e e-mail para acesso dos professores à atividade.

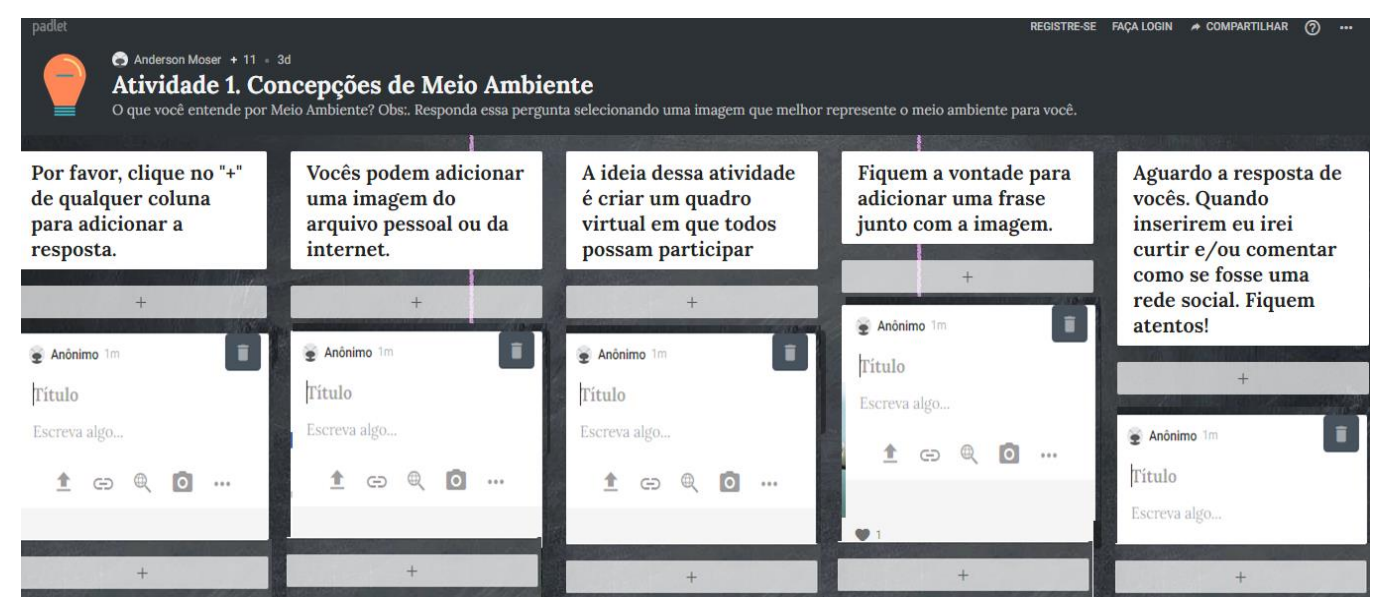

Figura 1: Padlet criado pelos autores para realização da atividade. Fonte: Adaptado do Padlet (PADLET, 2020).

No segundo encontro do processo formativo, foi realizada a discussão das imagens inseridas no Padlet. Para análise das concepções dos professores, foi exemplificado de forma expositiva, dialogada e com o auxílio de uma apresentação de slides, três concepções de ambiente de Sauvé (2005): natureza, recurso e objeto de transformação ou lugar de emancipação, bem como as macrotendências político pedagógicas da EA brasileira (conservacionista, pragmática e a crítica). Acredita-se que essas concepções de ambiente definidas por Sauvé (2005) apresentam íntima relação com macrotendências da EA brasileira identificadas por Layrargues e Lima (2011, 2014). Dessa forma, as concepções de ambiente e EA dos professores inseridas no Padlet foram analisadas sob a óptica do referencial teórico de Sauvé (2005) e de Layrargues e Lima (2011), conforme Quadro 1. 
Quadro 1. Macrotendências político-pedagógicas da EA brasileira.

\begin{tabular}{|c|c|c|}
\hline $\begin{array}{c}\text { Concepção de } \\
\text { ambiente } \\
\text { segundo Sauvé } \\
\text { (2005) }\end{array}$ & $\begin{array}{c}\text { Macrotendências } \\
\text { Político- } \\
\text { Pedagógicas da EA } \\
\text { segundo } \\
\text { Layrargues e Lima } \\
\text { (2011) }\end{array}$ & Principais características das macrotendências \\
\hline Natureza & Conservacionista & $\begin{array}{l}\text { É pautada nas correntes conservacionistas, } \\
\text { comportamentalistas e da alfabetização ecológica. } \\
\text { Entende o ambiente como algo distante das } \\
\text { relações sociais, políticas e seus variados conflitos } \\
\text { de interesses e de poder. Imersa nos princípios da } \\
\text { ecologia, compreende o ambiente como natureza, } \\
\text { portanto está vinculada à "pauta verde", como a } \\
\text { biodiversidade, ecoturismo, unidades de } \\
\text { conservação e biomas. }\end{array}$ \\
\hline Recurso & Pragmática & $\begin{array}{l}\text { Compreende as correntes de educação para o } \\
\text { desenvolvimento e consumo sustentável. Ela } \\
\text { poderia apresentar uma leitura crítica sobre as } \\
\text { problemáticas ambientais, no entanto, focaliza } \\
\text { apenas um viés pragmático. Voltada à "pauta } \\
\text { marrom" por ser essencialmente urbano-industrial, } \\
\text { compreende o ambiente como um recurso e um } \\
\text { problema, ou seja, percebe o ambiente como um } \\
\text { banco de recursos naturais em esgotamento, sendo } \\
\text { esse um problema a ser resolvido. }\end{array}$ \\
\hline $\begin{array}{c}\text { Objeto de } \\
\text { Transformação/ } \\
\text { Local de } \\
\text { Emancipação }\end{array}$ & Crítica & $\begin{array}{l}\text { Contempla as correntes de EA popular, } \\
\text { emancipatória, e transformadora, objetivando o } \\
\text { enfrentamento político das desigualdades de } \\
\text { classes e da injustiça ambiental. Compreende o } \\
\text { ambiente sob uma ótica socioambiental e crítica, } \\
\text { buscando contextualizar e politizar o debate } \\
\text { ambiental. }\end{array}$ \\
\hline
\end{tabular}

Fonte: Adaptado de Sauvé (2005) e Adaptado Layrargues e Lima (2011).

Para discussão das imagens, adaptou-se a metodologia utilizada por Kataoka et al. (2017), ou seja, projetou-se por meio de uma apresentação de slides cada imagem inserida no Padlet e em seguida, foi orientado que cada professor identificasse e explicasse o que sua imagem representava, além de classificá-la em uma concepção de ambiente e EA apresentadas anteriormente. $\mathrm{O}$ grupo foi instigado a contribuir na classificação das imagens.

No final do encontro, realizou-se uma breve exposição sobre o software Padlet, visando à formação dos professores para uma possível utilização da ferramenta como um recurso didático em suas práticas pedagógicas. 


\section{Participantes da Pesquisa}

Participaram da pesquisa um total de 14 professores, sendo que 13 eram atuantes na Educação Básica, pertencentes ao Núcleo Regional de Educação de Maringá-PR e um era professor do Ensino Superior privado.

Os professores foram comunicados sobre os procedimentos da pesquisa e o cuidado com a preservação do anonimato de cada um na publicação da investigação. Cada participante recebeu um Termo de Consentimento Livre e Esclarecido (TCLE) que, após a ciência de seu conteúdo, foi assinado. Assim, os participantes foram representados pelo código "P" (Participante) seguido do número atribuído a cada um deles, como por exemplo: P1; P2; P3... P14.

Para melhor análise dos dados, foram selecionadas algumas informações como o gênero, graduação, pós-graduação, disciplina que ministra e o tempo de magistério, a fim de evidenciar o perfil dos sujeitos investigados (Quadro 2).

Quadro 2. Perfil dos professores participantes da pesquisa.

\begin{tabular}{|c|c|c|c|c|c|}
\hline Cod. & $G^{*}$ & Graduação & Pós-Graduação & Disciplina & $T \cdot M^{\star \star}$ \\
\hline$P 1$ & $\mathrm{~F}$ & Ciências Biológicas & Mestrado & Ciências e Biologia & 10 anos \\
\hline$P 2$ & $\mathrm{~F}$ & Ciências e Matemática & Especialização & Ciências & 21 anos \\
\hline P3 & $\mathrm{F}$ & Ciências Biológicas & Mestrado & Ciências e Biologia & 30 anos \\
\hline$P 4$ & $F$ & Matemática e História & Especialização & Matemática & 30 anos \\
\hline P5 & $\mathrm{M}$ & Geografia & Especialização & Geografia & 10 anos \\
\hline$P 6$ & $F$ & Ciências Biológicas & Doutorado & Ciências e Biologia & 6 anos \\
\hline$P 7$ & $\mathrm{~F}$ & Ciências Biológicas & Especialização & Ciências e Biologia & 21 anos \\
\hline$P 8$ & $\mathrm{~F}$ & Ciências Biológicas & Mestrado & Biologia e EA & 20 anos \\
\hline$P 9$ & $\mathrm{~F}$ & Geografia & Especialização & Licença & 12 anos \\
\hline P10 & $\mathrm{F}$ & Ciências Biológicas & Mestrado & Ciências & 4 anos \\
\hline P11 & $\mathrm{F}$ & Ciências Biológicas & Doutorado & Ciências & 4 anos \\
\hline P12 & $\mathrm{F}$ & Pedagogia & Especialização & Pedagoga & 20 anos \\
\hline P13 & $\mathrm{M}$ & Design de Produto & Especialização & Diversas & 1 ano \\
\hline P14 & $\mathrm{F}$ & Ciências Biológicas & Mestrado & Biologia & $\begin{array}{c}2 \\
\text { meses }\end{array}$ \\
\hline
\end{tabular}

Fonte: Autores (2020). 


\section{Resultados e Discussão}

Os resultados referentes as análises do mural criado no Padlet pelos participantes encontram-se nos tópicos a seguir:

\section{As concepções de ambiente e EA dos professores}

No Padlet, os professores inseriram imagens que representavam suas concepções de ambiente. Na figura 2 é possível visualizar parte do Padlet criado pelos participantes.

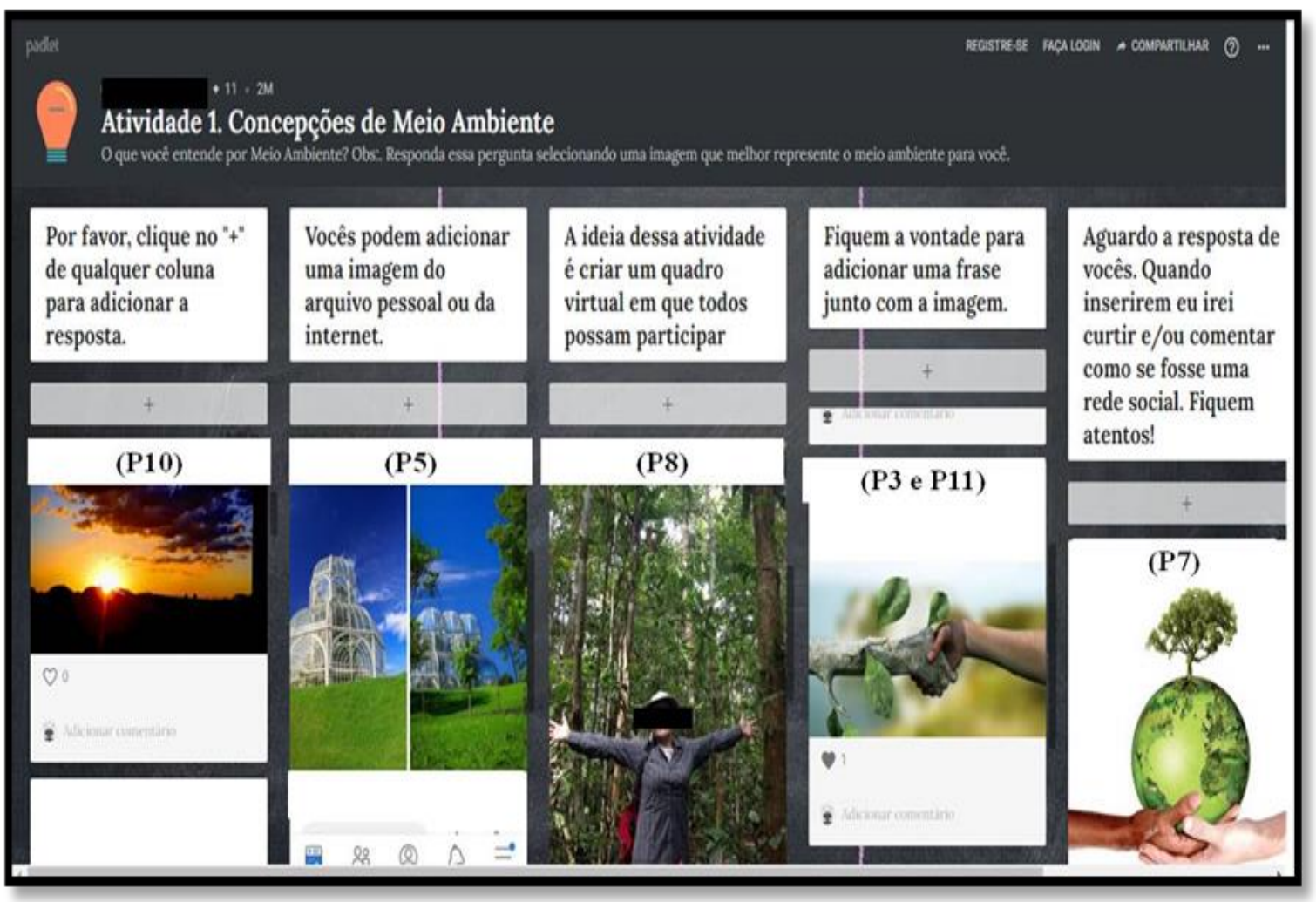

Figura 2: Mural criado no Padlet pelos professores participantes da pesquisa.

Fonte: adaptado do Padlet (2020).

Para Sato (2003), conhecer a maneira como os indivíduos percebem o ambiente é determinante para a sua atuação na EA. Assim, a estratégia adotada nesta pesquisa, associada ao uso das tecnologias da informação e comunicação (TICs), pode potencializar a inserção da temática ambiental no contexto escolar. Segundo Mota, Machado e Crispim (2017), a utilização das TICs com foco na EA representa um avanço, já que por meio dessa integração pode haver a sensibilização e o conhecimento do ambiente e seus problemas intrínsecos, muitos desconhecidos pela comunidade escolar que se encontra distante da sua realidade local. 
Diante do mural criado no Padlet e do registro da transcrição do áudio do segundo encontro do curso, foi averiguado que dez professores realizaram a atividade (P1; P3; P4; P5; P6; P7; P8; P10; P11 e P12) e quatro não a efetivaram (P2; P3; P9; P13 e P14). Constatou-se a predominância da concepção de ambiente como Natureza (P3, P4, P5, P6, P7, P8, P10 e P11), seguida pela concepção como Recurso (P4 e P11) e Objeto de transformação ou lugar de emancipação (P1 e P12) nas imagens postadas e classificadas pelos professores.

Oito professores classificaram suas imagens na concepção de ambiente como natureza e apresentaram um entendimento conservacionista sobre a EA. De acordo com os registros da transcrição do áudio do encontro, na explicação da sua imagem a professora P4 (matemática) destacou sua apreensão em apresentar sua representação de ambiente e EA diante de professores de Ciências, Biologia e Geografia, inferindo que a abordagem de temas ambientais é um assunto que recai somente a essas áreas do conhecimento. $A$ professora explicou sua imagem (Figura 3), mencionando que o ambiente é como "[...] uma terra rachada em formato de coração e que quando chove se revigora, da vida" [...]. Por isso eu coloquei coração verde". E reforçou que "[...] Tem que plantar mais árvores porque quem destruiu foi nós mesmos, matando nossas árvores".

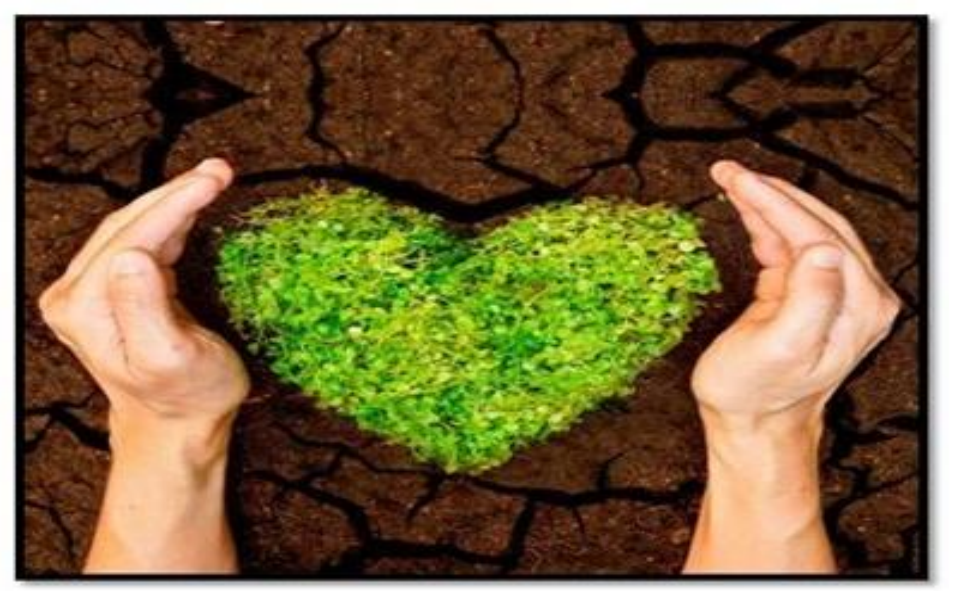

Figura 3: Concepção de ambiente como Natureza da professora P4 participante da pesquisa.

Fonte: P4.

As professoras P6 e P10 justificaram que as suas concepções naturalistas sobre 0 ambiente se relacionam às suas formações em Ciências Biológicas. A professora P6 assinalou que complementou sua imagem (Figura 4) com uma breve descrição: "na minha definição eu coloquei mais abrangente. Eu acho que de forma socioambiental" [...]. No entanto, com as reflexões oportunizadas com a discussão da atividade no segundo encontro, a participante passou por um processo de autoavaliação de sua concepção, apontando que sua imagem era condizente mais a uma visão naturalista do que uma concepção socioambiental. Para ela: "[...] biólogo vai pra passear, 
descansar, fazer uma trilha, mas acaba se encantando e registrando". Embora na imagem seja possível ver a presença do ser humano "[...] concordo que na imagem faltaram muitos elementos para ser considerada socioambiental” (P6).

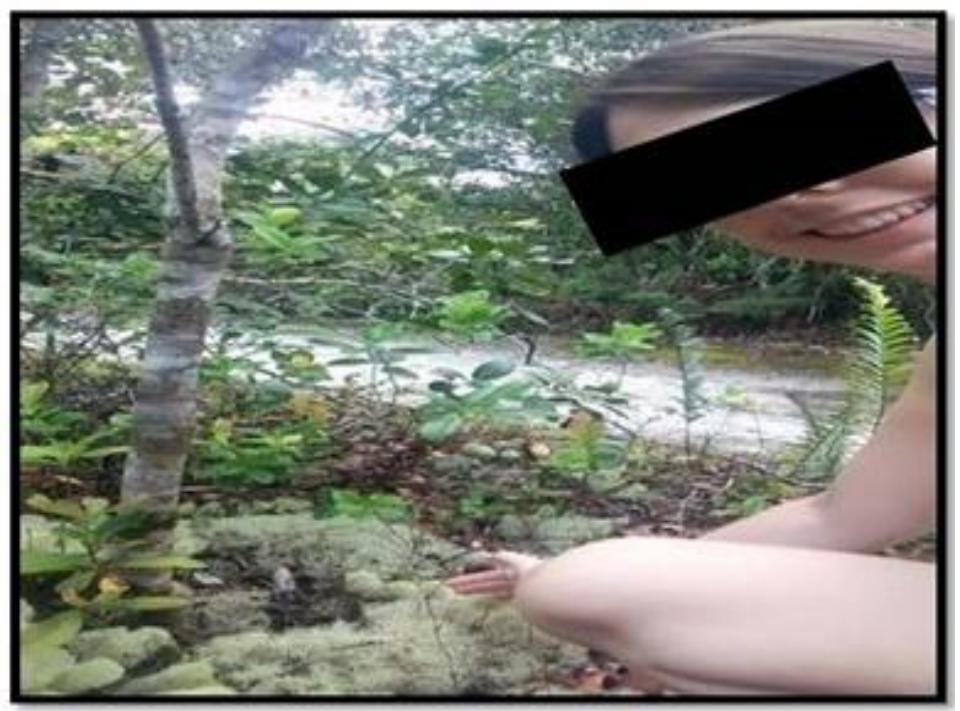

Figura 4: Concepção de ambiente como Natureza da professora P6 participante da pesquisa. Fonte: P6.

A discussão da atividade também promoveu a autoavaliação de P10 frente sua concepção sobre o ambiente. De acordo com a explicação de sua imagem (Figura 5), a professora ressaltou:

Agora que eu me toquei que a minha imagem é totalmente naturalista, mas é uma característica minha de ter essa visão naturalista. Até porque eu sou bióloga e não pensei de maneira alguma, só escolhi uma foto que mostra a minha visão (P10).

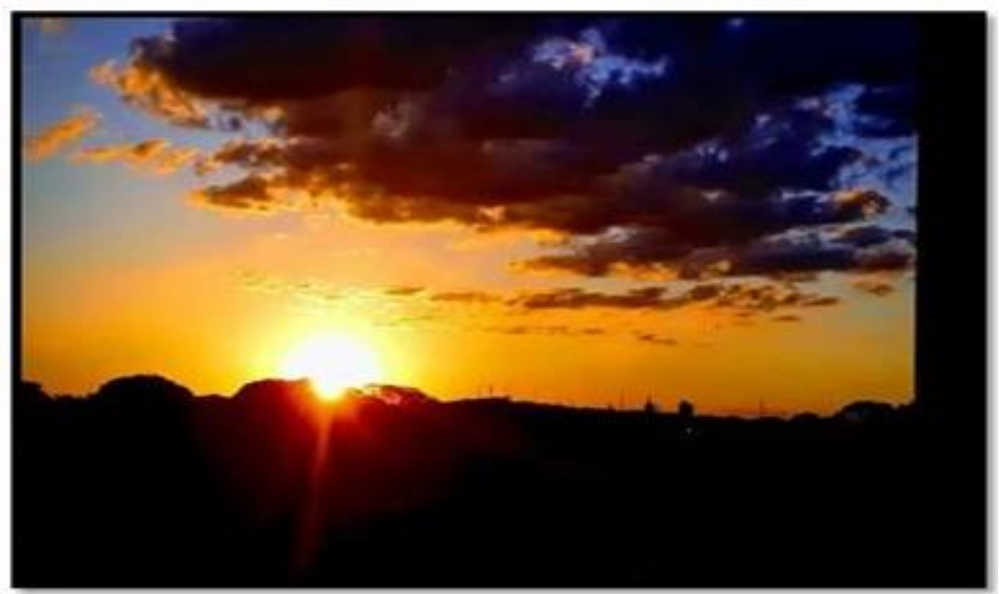

Figura 5: Concepção de ambiente como Natureza da professora P10 participante da pesquisa. Fonte: P10. 
As imagens relacionadas à concepção de ambiente como natureza reforçam os aspectos ecológicos e afetivos do ambiente. Nesta concepção, os seres humanos são reduzidos à condição de causadores e vítimas da crise ambiental, e a condição sociocultural é desconsiderada. Tal exemplificação mostra uma visão ingênua dos sujeitos da pesquisa ao desconsiderarem o meio ambiente como espaço de interação e transformação dos seres, em que o ser humano transforma e é transformado. Professores que apresentam uma concepção naturalista sobre 0 ambiente frequentemente desenvolvem nos espaços educativos práticas de EA conservacionistas. Ou seja, enfatizam ações direcionadas à conservação/preservação com ênfase na valorização de paisagens naturais e o bem-estar, mas não se discutem os aspectos da estrutura social, econômica, cultural e política que determinam a origem dos problemas socioambientais (LAYRARGUES; LIMA, 2011).

Diante do processo de autoavaliação das professoras P6 e P10 em relação às suas concepções naturalistas, percebe-se que houve o confronto entre a teoria com a prática, ou seja, o processo reflexivo oportunizado com a discussão da atividade na ferramenta Padlet favoreceu com que as participantes reavaliassem suas concepções sobre o ambiente. Resultado semelhante foi evidenciado por Kataoka et al. (2017), ao realizarem uma oficina de percepção ambiental com alunos do Ensino Médio, a qual promoveu a ampliação das concepções ingênuas de ambiente, representadas por imagens e descrições focadas nos aspectos naturais, constatando a ausência de integração do ser humano ao ambiente.

Nessa direção, Carvalho (2004) ressalta a necessária superação da visão naturalista para uma visão socioambiental, pautada na compreensão de que as dimensões naturais e sociais do ambiente se interagem e se modificam de forma dinâmica. Sendo assim, permitindo um olhar mais crítico sobre as relações que permeiam as questões ambientais em nível não apenas local, mas na sua globalidade, evidenciando a dinamicidade que integra todas as dimensões tanto as naturalistas quanto as sociais e culturais do ambiente.

Embora a professora P4 tenha classificado sua imagem como uma representação de ambiente enquanto natureza, observa-se a contribuição do grupo na classificação da imagem em outra concepção. Nesse exemplo, a professora $\mathrm{P} 6$ complementou que a imagem também se refere à proteção $\mathrm{e}$ preservação humana em relação ao ambiente, representada pelas mãos envoltas no coração verde, ou seja, o ser humano cuida do ambiente porque precisa dele. O depoimento de P6 sugere que a imagem confirma a presença da concepção como um recurso. Dessa forma, os participantes puderam constatar que em uma mesma definição sobre o ambiente há a possibilidade de sobrepor mais de uma concepção, conforme relata Sauvé (2005).

Outra compreensão de ambiente, classificada como natureza e recurso, emergiu da imagem de P11 (Figura 6). De acordo com a professora, sua imagem refletia o ambiente devido representar o "[...] equilíbrio na relação do homem com os serviços ecossistêmicos". Complementou que mesmo que o 
"Desenvolvimento Sustentável" seja difícil de ser atingido, as tentativas devem continuar, pois a "EA está aí pra isso" (P11). Entende-se que a visão recursista sobre o ambiente implica no desenvolvimento de práticas de EA pragmáticas. Para Layrargues e Lima (2011), a macrotendência pragmática deriva da conservacionista, por esse motivo as suas definições se aproximam. Todavia, o pragmatismo na EA se vincula ainda mais aos anseios do mercado, na medida em que se adapta ao contexto social, econômico e tecnológico, porém sem considerar os processos sociais e culturais que legitimam os problemas socioambientais. Para os autores, ambas são comportamentalistas e individualistas, mas a conservacionista é uma concepção mais ingênua sobre as questões ambientais.

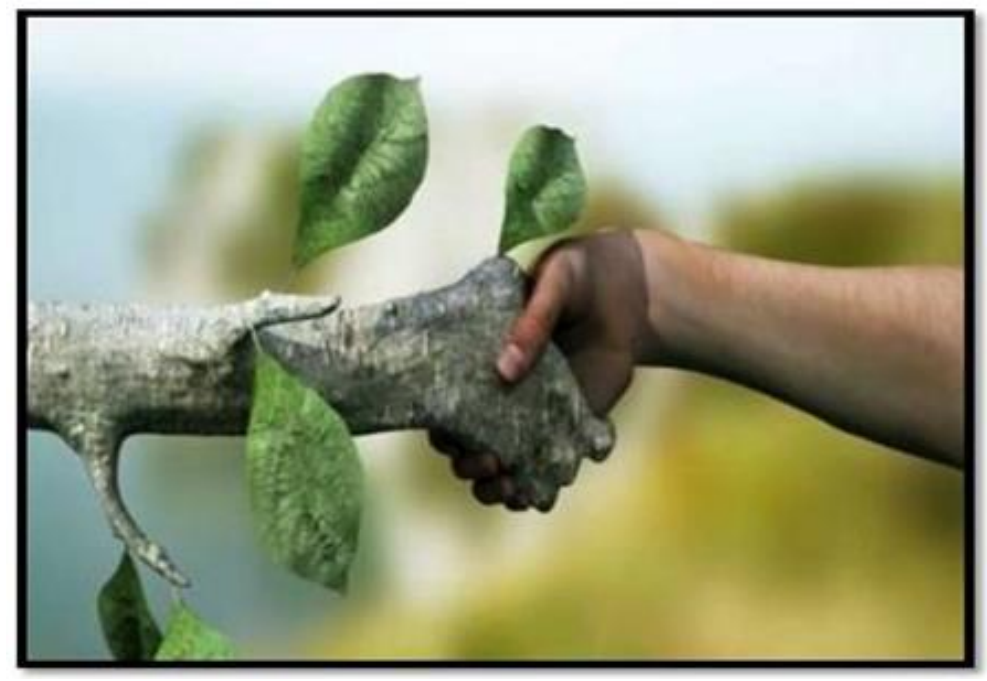

Figura 6: Concepção de ambiente como Recurso e Natureza da professora P11. Fonte: P11.

As concepções de ambiente como natureza e recurso foram expressivas na maioria das imagens postadas pelos professores na ferramenta Padlet. Oliveira, Obara e Rodrigues (2007) apontaram resultado semelhante ao investigarem as percepções e práticas pedagógicas de professes de Ciências sobre a EA. Segundo os autores, de acordo com esse modo de conceber o ambiente, os professores evidenciam um entendimento antropocêntrico sobre as questões ambientais, baseada no pensamento cartesiano que fragmenta 0 social do natural.

Duas professoras postaram imagens no Padlet próximas de uma concepção socioambiental/crítica sobre o ambiente e a EA. Com base na transcrição do áudio do encontro, a professora P1 (Ciências e Biologia) relatou que "[...] o ambiente é onde eu vivo, minha casa, a rua onde eu moro", conforme demonstra a Figura 7-P1. A imagem postada pela professora P12 (pedagoga) também representa a concepção de ambiente como objeto de transformação/local de emancipação. De acordo com a participante, sua imagem é referente à horta presente na escola do campo em que trabalha 
(Figura 7-P12). A equipe pedagógica e professores utilizam este espaço para desenvolverem projetos interdisciplinares que envolvem a comunidade escolar e do entorno. A professora P12 exemplificou que no momento da presente pesquisa (mês de abril de 2019) a horta contava com plantações de batata inglesa e batata doce, com um projeto voltado para a aprendizagem da matemática. $\mathrm{O}$ projeto se justificava pela dificuldade apresentada pelos alunos em relação à disciplina. Entretanto, a horta possibilita outras discussões, como a controvérsia dos agrotóxicos, enfatizada no depoimento da participante:

[...] existem professores que defendem o uso o agrotóxico e aí chega a dizer que ninguém precisa saber que o nosso não é orgânico, defendendo a necessidade de usar. E, por outro lado, professores que são contra o uso dessas substâncias (P12).

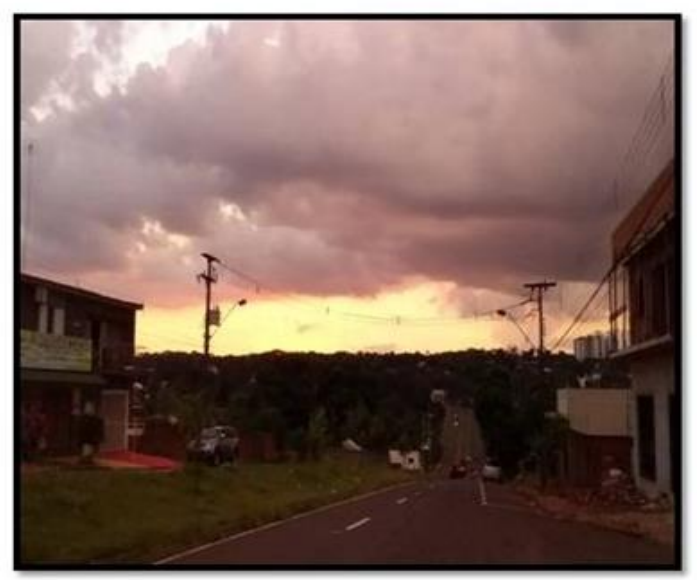

(P1)

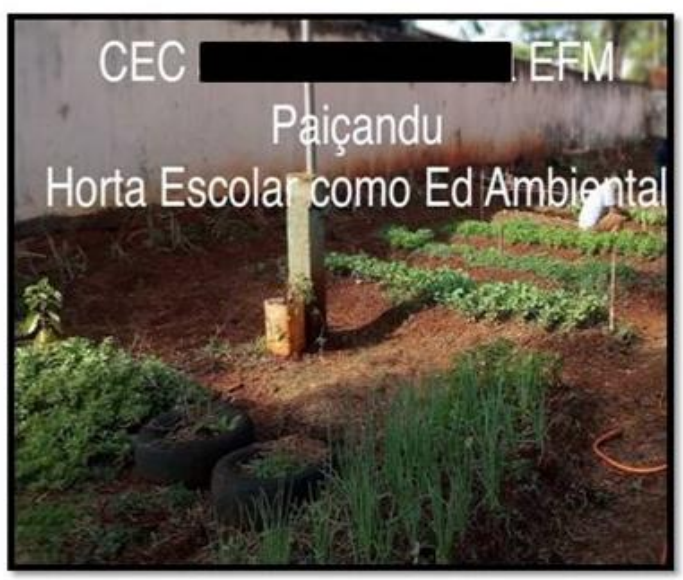

(P12)

Figura 7: Concepção de ambiente como Objeto de transformação/Local de emancipação das professoras $\mathrm{P} 1$ e $\mathrm{P} 12$ participantes da pesquisa.

Fonte: $\mathrm{P} 1$ e $\mathrm{P} 12$.

Reforçou-se junto aos professores que a horta escolar pode funcionar como um recurso acessível no contexto escolar para abordagem da EA sob uma perspectiva crítica, tendo em vista que pode envolver a participação dos alunos, professores, comunidade do entorno e diferentes conhecimentos científicos e populares relacionados ao tema. Envolve também a reflexão sobre problemas inerentes ao espaço escolar, bem como, o debate socioambiental relacionado ao uso de agrotóxicos e a alimentação saudável. De acordo com Layrargues e Lima (2011, p. 11) a EA crítica se constitui em oposição à macrotendência conservacionista e pragmática de EA, na intenção de "[...] contextualizar e politizar o debate ambiental, articular as diversas dimensões da sustentabilidade e problematizar as contradições dos modelos de desenvolvimento e de sociedade". Assim, as discussões podem se relacionar com aspectos do âmbito local (como evidenciado por P12 pelo uso de agrotóxicos), possibilitando transcender as discussões em nível global. 
Vale destacar que as classificações realizadas pelas professoras $\mathrm{P} 1 \mathrm{e}$ P12 foram efetuadas de acordo com o suporte teórico apresentado pelos pesquisadores na explanação das concepções de ambiente e EA no primeiro momento do segundo encontro do curso. Assim, diante das três concepções de ambiente abordadas (Natureza, Recurso e Objeto de transformação/local de Emancipação) a concepção que mais se aproximou das imagens postadas pelas participantes P1 e P12 foi a "Objeto de transformação/local de Emancipação". Todavia, na visão dos pesquisadores, faltaram elementos para que tanto a imagem de P1 quanto a imagem de P12 fossem categorizadas como "Objeto de transformação/Local de Emancipação". Com base nas correntes de EA definidas por Sauvé (2005), a concepção de ambiente relacionada à classificação das participantes diz respeito a uma EA como "crítica social", ou seja, tem como direcionamento "Desconstruir as realidades socioambientais visando transformar o que causa problemas" (SAUVÉ, 2005, p. 41). Dessa forma, como podemos observar nos depoimentos de P1 e P12, bem como nas suas imagens (Figura 5), não foram evidenciadas as diferentes dimensões (social, cultural, politica, ética, econômica, etc) que envolvem as questões ambientais e que são de fundamental importância para a compreensão e enfrentamento dos problemas.

Embora as imagens de $\mathrm{P} 1$ e $\mathrm{P} 12$ não correspondessem exatamente a uma concepção de ambiente pautada numa visão socioambiental, verificou-se que por meio das intervenções promovidas pelo curso de formação continuada, as professoras puderam ampliar suas concepções sobre o ambiente e a EA, em relação às suas concepções iniciais investigadas no questionário préintervenção. Essa inferência se deve ao fato de que ambas as professoras mostraram em suas imagens e depoimentos aspectos que se aproximam mais para um entendimento de ambiente como objeto de transformação ou local de emancipação em vez de uma concepção de ambiente sob a óptica de elementos ecológicos ou naturalistas. Sobre esse aspecto, Lima e Oliveira (2011) também observaram modificações conceituais de concepções de professores de escolas públicas. As reflexões oportunizadas em um curso de formação continuada possibilitaram com que os professores ampliassem suas concepções naturalistas sobre 0 ambiente e a EA em concepções socioambientais.

Diante do exposto, buscou-se no decorrer dos demais encontros do curso de formação continuada trazer elementos que favorecessem para que todos os participantes da pesquisa se apropriassem e ampliassem suas visões sobre o ambiente e a EA.

\section{Reflexões sobre o uso da ferramenta Padlet no ensino da EA}

Após a análise das concepções de ambiente e EA dos professores, foi realizada uma breve explicação sobre o funcionamento do Padlet, de modo que os participantes, caso desejassem, pudessem utilizar o software como um recurso didático em suas práticas pedagógicas, corroborando com a pesquisa 
de Silva e Lima (2018) realizada com professores da Educação Básica. Os autores consideraram que o Padlet serve como um ambiente virtual de aprendizagem acessível por apresentar um layout com fácil navegação pelos usuários. Sendo assim, tal experiência pode favorecer com a autonomia e sistematização dos alunos em processos de ensino e aprendizagem no ciberespaço.

O Padlet se caracterizou como um importante instrumento capaz de potencializar a ação educativa e ambiental sob um viés interativo. Seu uso em consonância com a estratégia de ensino adotada no curso de formação continuada proporcionou aos professores uma reflexão sobre as suas concepções de ambiente e EA. Puderam, também, evidenciar que tais concepções podem ser investigadas de forma mais dinâmica, como uma alternativa a recursos tradicionalmente utilizados como questionários, entrevistas, desenhos, entre outras possibilidades.

Os subsídios teóricos e práticos oportunizados por meio da utilização da ferramenta visaram oportunizar uma formação para que em momentos futuros os professores utilizem o Padlet em suas práticas com os alunos. Podendo eles, investigar as concepções de ambiente e EA ou até mesmo desenvolver outras práticas que remetam ao caráter interdisciplinar e crítico sobre a questão ambiental, conforme recomendações da Diretriz Curricular Nacional de EA (BRASIL, 2012).

O uso do software Padlet exigiu dos professores o trabalho com as TICs (computador, celular, internet, e outras tecnologias). Pôde-se observar que nem todos os professores apresentam o domínio para o trabalho com as TICs, conforme aponta o depoimento da professora P4: "Não consegui mexer nessa ferramenta e tive que solicitar ajuda de um colega". Sobre esse aspecto, Zanella e Lima (2017) comentam que os professores apresentam ciência da importância significativa do uso das TICs nos processos pedagógicos com os alunos, sendo que quanto mais jovens os professores, menores são as dificuldades apresentadas. Todavia, um dos principais desafios a serem superados no contexto escolar é o uso das tecnologias no ensino, bem como a ineficaz ou inexistente formação para a utilização das TICs. Velho et al. (2016) complementam que as TICs (como é o caso do Padlet), quando incorporadas na educação, exigem dos professores uma reflexão da sua prática pedagógica e uma formação alinhada com as tecnologias. Para os autores, a EA não precisa apenas de professores com tal compreensão, mas também que consigam de modo interdisciplinar atrelar e desenvolver estratégias que possibilitem aos alunos vivenciar o processo educativo. 


\section{Considerações Finais}

Com base no objetivo da presente pesquisa, constatou-se que a ferramenta Padlet se mostrou como um instrumento importante para conhecer as concepções de ambiente e EA dos professores participantes dessa investigação. Seu layout didático e a facilidade de manuseio possibilitou que os participantes inserissem de modo simples a imagem que lhes representava 0 ambiente e EA, respectivamente.

No que se refere às possibilidades e à versatilidade, cabe destacar que a ferramenta pode ser tanto utilizada em processos formativos continuados de professores, como é o caso desta pesquisa, como também ser uma ferramenta que auxilie o professor em sala de aula, com este replicando a metodologia e o uso do Padlet com os alunos.

Entre as concepções dos professores, o Padlet nos possibilitou evidenciar a predominância da concepção de ambiente como natureza, representando um entendimento conservacionista de EA. A maior ocorrência desta concepção pode ser justificada pelo fato de a concepção de ambiente como natureza convergir a uma tendência conservadora, histórica, forte e consolidada no campo da EA.

Nesse sentido, destaca-se a relevância em ofertar processos de formação continuada pautados em subsídios teóricos e práticos sob a perspectiva crítica da EA, os quais possam fornecer aos professores condições para ampliar suas concepções sobre a temática ambiental. Ou seja, transcender a compreensão conservacionista e pragmática de EA, considerando também as dimensões sociais, culturais, econômicas e políticas que compõem a visão socioambiental sobre as questões ambiental.

Assim, o uso de tecnologias, mais especificamente a ferramenta Padlet, pode desempenhar uma função importante como instrumento de pesquisa e ensino para a investigação de concepções de ambiente e EA. A partir das informações fornecidas por meio da utilização da ferramenta, pode-se construir uma abordagem, levando em consideração as ideias, concepções e representações do público alvo, contribuindo para uma maior possiblidade de êxito na ação desenvolvida.

\section{Referências}

BRASIL. Lei no. 9.795, de 27 de abril de 1999. Dispõe sobre a educação ambiental, institui a Política Nacional de Educação Ambiental e dá outras providências.

Disponível: $<$ http://www.planalto.gov.br/ccivil 03/Leis/L9795.htm>. Acesso em: 03 ago. 2019.

BRASIL. Resolução no 2, de 15 de junho de 2012. Estabelece as Diretrizes Curriculares Nacionais para a Educação Ambiental. Disponível em:<http://conferenciainfanto.mec.gov.br/images/conteudo/ivcnijma/diretrizes.pdf> Acesso em 14 junho 2019. 
CARVALHO, I. C. M. Educação ambiental: a formação do sujeito ecológico. 4 ed. São Paulo: Cortez, 2004.

GARRIDO, L.; MEIRELLES, R. Percepção sobre meio ambiente por alunos das séries iniciais do ensino fundamental: considerações à luz de Marx e de Paulo Freire. Ciência \& Educação, v. 20, n. 3, p. 671-685, 2014.

JACOBI, R. P. Educação ambiental: o desafio da construção de um pensamento crítico, complexo e reflexivo. Educação e Pesquisa, v. 31, n. 2, p. 233-250. 2005.

KATAOKA, A. M.; AFFONSO, A. L. S.; MOSER, A. S.; FISS, B. K.; MATAKAS, B. G. Reflexão sobre alternativas metodológicas para a inserção da educação ambiental crítica no ambiente escolar. Revista Brasileira de Ensino de Ciência e Tecnologia, v. 10, n. 1, p. 1-17, 2017.

LAYRARGUES, P. P.; LIMA, G. F. C. Mapeando as macro-tendências políticopedagógicas da educação ambiental contemporânea no Brasil. In: VI Encontro Pesquisa em Educação Ambiental, 2011, Ribeirão Preto. Anais... Ribeirão Preto: USP, p. 01-15, 2011. Disponível em: http://www.epea.tmp.br/viepea/files.epea2011.webnode.com.br/20000013264f2b65ec6/epea2011-0127-1.pdf. Acesso em 21 julho 2019.

LAYRARGUES, P. P.; LIMA, G. F. DA C. As macrotendências políticopedagógicas da educação ambiental brasileira. Ambiente \& Sociedade, v. 17, n. 1, p. 23-40, mar. 2014.

LIMA, A.M.; OLIVEIRA, H. T. A. (re) construção dos conceitos de natureza, meio ambiente e educação ambiental por professores de duas escolas públicas. Ciência \& Educação, v. 17, n. 2, p. 321-337, 2011.

LUDKE, M.; ANDRÉ, M. E. D. A. Pesquisa em educação: abordagens qualitativas. São Paulo: Ed. EPU, 1986.

MOTA, K. M.; MACHADO, T. P. P.; CRISPIM, R. P. S. Padlet no contexto educacional: uma experiência de formação tecnológica de professores. Revista Educacional Interdisciplinar, v. 6, n. 1, p. 1-8, 2017.

OLIVEIRA, A. L.; OBARA, A. T.; RODRIGUES, M. A. Educação ambiental: concepções e práticas de professores de ciências do ensino fundamental. Enseñanza de las Ciencias, v. 6, n. 3, p. 471-495, 2007.

PADLET. O Padlet é o jeito mais fácil do mundo para criar e colaborar, 2020. Disponível em: https://pt-br.padlet.com/. Acesso em: 30 julho 2020.

REIGOTA, M. Meio ambiente e representação social. São Paulo: Cortez, 2005.

SATO, M. Educação ambiental. São Carlos: Ed. Rima, 2003. 
SAUVÉ, L. Uma cartografia das correntes em educação ambiental. In: SATO, M.; CARVALHO, I. C. M. (Orgs.). Educação Ambiental. São Paulo: Editora Artmed, 2005 ,

p. $\quad 17-46$.

Disponível

em:

https://edisciplinas.usp.br/pluginfile.php/4586522/mod resource/content/1/sauv e\%20correntes\%20EA.pdf. Acesso em 24 julho 2019.

SILVA, P. G.; LIMA, D. S. Padlet como ambiente virtual de aprendizagem na formação de profissionais da educação. RENOTE - Revista Novas Tecnologias na Educação, v. 16, n. 1, p. 1-10, 2018.

VELHO, A. R. T.; MAURELL, J.; BARWALDT, R.; ROSA, V. Trabalhando a problemática ambiental ao viés de quadros colaborativos online: uma ação no contexto escolar. V Congresso Brasileiro de Informática na Educação (CBIE 2016). Anais... XXII Workshop de Informática na Escola - WIE, p. 446-455, 2016.

Disponível

em:

https://www.researchgate.net/publication/309883174 Trabalhando a Problema tica Ambiental ao Vies de Quadros Colaborativos Online Uma Acao no C ontexto Escolar. Acesso em 25 julho 2019.

VILLAR, L.M.; ALMEIDA, A. J.; LIMA, M. C. A.; ALMEIDA, J. L. V.; SOUZA, L. F. B.; PAULA, V. S. A percepção ambiental entre os habitantes da região noroeste do estado do Rio de Janeiro. Escola Anna Nery Revista de Enfermagem, v. 12, n. 2, p. 285-290, 2008.

ZANELLA, B. R. F.; LIMA, M. F. Refletindo sobre os Fatores de Resistência no Uso das TICs nos Ambientes Escolares. Scientiacum Industria, v. 5, n. 2, p.78-89, 2017.

ZUPELARI, M. F. Z.; WICK, M. A. L. A incerteza do futuro e a questão ambiental na contemporaneidade. Revista Subjetividades, v.15, n.3, p. 447456, 2015. 